\title{
SOBRE O COMEÇO TRIÁDICO DA LÓGICA HEGELIANA: O SER, O NADA, O DEVIR
}

\author{
Marcos Fábio Alexandre Nicolau ${ }^{1}$
}

\begin{abstract}
RESUMO: A recusa hegeliana a todo Absoluto intuído ou posto irrefletidamente exigiu a elaboração de um sistema filosófico inteligível e discursivo do princípio ao fim. A ideia daí decorrente é que a possibilidade de inteligibilidade deste Absoluto é correlata à possibilidade de sua exposição. Ou seja, a necessidade a ele inerente, que precisa produzir seus próprios conteúdos, exteriorizando-se e ao mesmo tempo reconhecendo sua identidade consigo mesmo, provando a necessidade do começo na efetivação de um sistema da ciência que tem por base um projeto de uma ciência da lógica fundadora da própria ciência em si mesma. Assim, o desenvolver de um princípio primeiro-último especulativo, na filosofia hegeliana, marca o papel inequívoco de mediador, no sentido de liberar o sistema de métodos e propostas exteriores e contingentes que ainda o condicionam. O resultado disso é que, na Ciência da Lógica, a pressuposição de um começo imediato e vazio do sistema científico-filosófico das categorias do Absoluto, e o discurso metodológico pelo qual ele se expõe, precisam ser descritos e explicados, devido justamente ao caráter incondicional do pensamento puro, no qual se estrutura tais bases para o dito sistema.
\end{abstract}

Palavras-chave: Doutrina da Ciência; Método Dialético; Absoluto

Résumé: La refuse hégélienne par tout ce qui est absolu déduit ou posé sans réfléchir a exigé l'élaboration d'un système philosophique intelligible et discursif du début à la fin. L'idée parvenu de cela c'est que la possibilité d'intelligibilité de cet absolu est corrélative à la possibilité de son exposition. Ainsi, le développement d'un principe avant-dernier spéculatif, dans la philosophie hégélienne, marque le rôle sans équivoque de médiateur, dans le sens de libérer le système de méthodes et propositions extérieures et contingentes. Le résultat de cela c'est que dans la Science de la Logique, la présupposition d'un début immédiat et vide du système scientifique-philosophique des catégories de l'absolu, et le discours méthodologique par lequel il s'expose, on besoin d'être décrits et expliqués, justement à cause de son caractère inconditionnel de la pensé pure, dans laquelle est structurée les bases de ce système.

Mots-clé: Doctrine de la Science; Méthode Dialectique; Absolu

Uma observação que podemos fazer sobre este tão famoso passo primeiro da Lógica de Hegel, a saber, a dialética de ser-nada-devir, é que nele se utilizam conceitos não deduzidos nem explicados previamente. Conceitos como igualdade, movimento,

\footnotetext{
${ }^{1}$ Mestre em Filosofia pelo Programa de Pós-Graduação em Filosofia da ICA/UFC. Doutorando em Educação do Programa de Pós-Graduação em Educação Brasileira FACED/UFC, com bolsa Funcap. Artigo submetido em 14 de dezembro de 2010.
} 
imediatidade e mediação, identidade e diferença etc., que são pressupostos por nós a partir do momento que decidimos pensar. ${ }^{2}$ Não poderia ser de outro modo, pois, quando falamos e analisamos, utilizamos conceitos, e um discurso sobre o começo não poderia fugir dessa necessidade. É claro, tais conceitos são justificados no decorrer da obra hegeliana, porém, isso demonstra que não cabe começar por algo simples tão somente, por um pensamento sem determinação, como aparenta pretender fazer Hegel na Lógica. Disso se segue que há uma diferença entre os conceitos operativos do pensar e sua tematização, revelando que é, desde sempre, preciso usar as determinações da reflexão quando se tem que emitir um enunciado. Pois, não se pode formular uma proposição sem que, com isso, entrem já em jogo as categorias da identidade e da diferença. Mas, Hegel não começa sua Lógica com as categorias da identidade e da diferença, já que, ainda que houvesse querido desenvolver, já desde o princípio, estas categorias da reflexão, teria que pressupor já a este respeito tanto a identidade quanto a diferença. Todo aquele que formula proposições utiliza palavras distintas e entende por cada uma isso ou aquilo, considerando assim ambas as categorias, identidade e diferença, como já aí implicadas.

A intenção sistemática de Hegel, por consequência, lhe prescreve outra forma de construção. Em sua proposta de deduzir a recíproca conexão de todas as categorias, adota um critério que lhe vem dado pela determinação enquanto tal. Todas as categorias são, certamente, determinações do conteúdo do saber, isto é, do conceito. Posto que o conteúdo deve avançar na pluralidade de sua determinação, de forma a obter a verdade do conceito, a ciência tem de começar com aquilo no qual haja o mínimo de determinação. Tal é o critério para a construção da lógica hegeliana: partir do mais geral, isto é, do minimamente determinado, no qual, por assim dizer, o que há de conceber não é quase nada, para progredir constantemente para o pleno conteúdo do conceito e avançar assim à totalidade do conteúdo do pensar. (Cf. GADAMER, 2000, p. 85-86)

\footnotetext{
${ }^{2} \mathrm{O}$ que nos remete à crítica de Kierkegaard: se toda forma de ciência deve partir de um pressuposto, como já fora exposto por Fichte e Schelling, é condição científica o começo, e se a Lógica segue tal condição, não seria o projeto hegeliano nessa obra condicionado por seu começo? Como justificar, então, o almejado estatuto de saber absoluto, ou seja, incondicionado? Dessa forma, conclui o filósofo dinamarquês: "o começo só pode ser realizado se a reflexão for interrompida, e a reflexão só pode ser interrompida através de alguma outra coisa, e essa outra coisa é algo totalmente diferente do lógico, pois é uma decisão.” (KIERKEGAARD, 1991, p. 106. Apud. LUFT, 2001, p. 50)
} 
Por isso, podemos pressupor que Hegel não seja tão ingênuo, a ponto de ser surpreendido por tal situação, ele sabe disso, sabe que não há nada simples, que o ser com que se começa pressupõe a abstração de todo determinado, de todas as mediações, e sabe que é isso que o iguala ao nada, pois

A exigência de um começo é uma exigência ilusória quando pretende um início absoluto, o primeiro imediato que não seria ele mesmo mediação. No entanto, o saber absoluto parte do ser, mas este ser é ao mesmo tempo implicitamente o saber do ser, é a mediação que se apresenta como a passagem do ser ao nada e do nada ao ser, a determinação de um pelo outro. (HYPPOLITE, 1991, p. 85)

Logo, é um passo necessário, que confirma a tese hegeliana que em absolutamente nada se pode prescindir de ser e nada, da mediação e imediatidade. Porém, na busca de constatar possíveis soluções que Hegel propõe a questões semelhantes, nos propomos analisar as notas de Hegel a esse começo triádico, encontradas na doutrina do ser, nas quais busca responder e esclarecer essas dúvidas levantadas contra seu projeto de uma ciência da lógica, que realmente assumiria a posição de uma doutrina da ciência.

Hegel acrescenta em nota que o nada trata "da negação abstrata, imediata, o nada puro por si, a negação carente de relação" (HEGEL, 1992, p. 108-109). Ser e nada são a mesma coisa, Hegel conclui tal assertiva, ainda que tenha a certeza de que ambos são diferença absoluta um do outro. Porém, são inseparados e inseparáveis, como bem afirma Wahl (1959, p. 2),

Por conseguinte, não se trata de opor, por exemplo, o ser, que seria o geral, e a determinação, que seria o particular. A determinação, ou seja, o Não-ser, a particularidade, ainda não se destacou do ser. Aliás, nunca será completamente destacada. Porque o que está no fundamento de toda esta dialética, é a unidade do nada com o ser, e todas as determinações produzemse a partir de esta unidade primeira do ser e do não-ser. E nós reafirmamos que há uma unidade imediata dos dois, de modo que não há diferenciação entre os dois.

Tal unidade é tida por Hegel como a própria realidade, que antes de tudo é dialética, pois a verdadeira realidade se constitui não só de ser e nem só de nada, mas 
sim de um transpassar de um transpassado ao outro, da passagem constante do ser no nada e do nada no ser. $\mathrm{O}$ ser se transforma no nada ao mesmo tempo em que o nada se transforma em ser, de forma que pensar em um deles já é pensar no outro, pois este "cair no outro" é algo tão incessante que não há forma de tê-los separadamente, a isso Hegel chama o devir: o constante nascer-morrer, que faz com que tanto o ser como o nada desapareceram e reapareçam um no outro. Assim, "o devir implica que o nada não permaneça como nada, senão que transite a seu outro, ao ser" (HEGEL, 1992, p. 109) e vice-versa. Mas dessa dialética surge uma negação da negação, que se torna uma afirmação, ou seja, um positivo, que aqui na Lógica será anunciado como ser, nesse caso, o ser-aí ${ }^{3}$ que surge do devir.

A realidade é dialética justamente porque "em nenhum lugar, nem no céu nem na terra, há algo que não contenha em si ambos, o ser e o nada" (HEGEL, 1992, p. 110). Assim, ser e nada têm um papel fundante, eles são o verdadeiro princípio da filosofia, nesse caso, de qualquer coisa, pois ambos explicitam o começo da ciência:

Posto que esta unidade de ser e nada está agora, de uma vez por todas, colocada na base como verdade primeira e constitui o elemento de tudo o que se segue, são exemplos de esta unidade, ademais do devir mesmo, de todas as ulteriores determinações lógicas: o ser-aí ou existência (Dasein), a qualidade e em geral todos os conceitos da filosofia. (HEGEL, 1992, p. 111)

A defesa hegeliana da proposição de que ser e nada são o mesmo é, ao mesmo tempo, uma crítica àquela outra posição que pensa surgir daí um ser-aí e um nada determinado, o que neste momento é algo inviável, já que na doutrina do ser não há qualquer tipo de determinação, e se no decorrer do texto usamos o termo determinação para conceitos próprios da doutrina do ser o fizemos para evidenciar o processo de determinação que age na Lógica, ou seja, a dialética, mas daí não se pode deduzir que há algum conceito efetivamente determinado nesse momento. Logo, não se pressupõe um ser ou um nada determinados, nem se chegará, nesse momento, a tais determinações, pois se está no âmbito do ser que está em relação ou mediação consigo mesmo, e

\footnotetext{
${ }^{3}$ O ser-aí aqui exposto é referente ao Dasein, que recebe como outras traduções existência e ser determinado. Embora saibamos que Hegel não dá um sentido unívoco ao termo, elegermos a tradução seraí em nosso texto, por ser mais utilizado na tradução da lógica com que trabalhamos.
} 
Um ser determinado, finito, é um ser tal que se refere a outro; é um conteúdo que está em uma relação de necessidade com outro conteúdo, com o mundo inteiro [...] as abstrações do ser e do nada deixam ambas de ser abstrações quando adquirem um conteúdo determinado. (HEGEL, 1992, p. 112-113)

Por isso qualquer determinação somente se dará na doutrina da essência, onde o ser realmente aparece, se manifesta, se pondo como relação.

Passemos então a considerar a natureza do começo dialético da ciência, configurado na tríade ser-nada-devir, que, para Hegel, é uma verdade especulativa. Segundo o filósofo, a dificuldade sentida por alguns de seus opositores para compreender sua proposta de como deve começar a ciência, se deve ao fato de que esses se baseiam em proposições tidas na forma de juízos, que não são aptas para expressar verdades especulativas (HEGEL, 1992, p. 117-118), pois os juízos se referem a identidades ou diferenças, "uma relação de identidade entre sujeito e predicado" (HEGEL, 1992, p. 118). O especulativo é dialético, trazendo à tona proposições que apresentam paradoxos e extravagâncias para quem não está familiarizado com tal método. ${ }^{4} \mathrm{O}$ especulativo não pode ser tido unilateralmente, pondo uma proposição como sendo mais verdadeira, ou com um maior valor de verdade que a outra, pois assim se elimina a dialética, que só ocorre pelo reconhecimento do valor das proposições.

Assim, embora se tenha criado uma identidade entre ser e nada por sua vacuidade, não se desprezou o fato de ambos terem estatutos próprios que os diferenciam um do outro, dessa forma Hegel apresenta uma premissa importantíssima ao devir, pois "no devir os dois se encontram como distintos; o devir existe só enquanto eles são distintos" (HEGEL, 1992, p. 120). ${ }^{5}$ E é este caráter de oposição, que conserva os valores de ser e nada, que faz da dialética o motor do processo.

\footnotetext{
${ }^{4}$ Por isso, Hegel alerta: “A injustiça mais comum contra o pensamento especulativo, consiste em torná-lo unilateral, isto é, em salientar apenas uma das proposições em que pode resolver-se. Então não pode negar-se que esta proposição se encontre afirmada; tanto quanto é exata a afirmação, outro tanto é falsa, porque quando se toma uma proposição da esfera especulativa, deveria pelo menos ser tida em conta e declarada igual e juntamente a outra." (HEGEL, 1992, p. 118)

${ }^{5}$ Hegel diz: "Desta maneira o resultado total e verdadeiro, que se chegou aqui, é o devir, que não é puramente a unilateral ou abstrata unidade do ser e do nada, senão que consiste no movimento seguinte: $o$ puro ser é imediato e simples, portanto, é igualmente o puro nada, e a diferença entre eles existe, porém ao mesmo tempo se elimina e não existe. O resultado afirma, pois, também a diferença entre o ser e o nada, porém uma diferença apenas entendida. Se entende que o ser é antes, absolutamente, outro que o
} 
Vê-se aqui uma mediação, ou a forma, o modelo, como ocorre a mediação, já que nesse momento não ocorre nenhum tipo de determinação, relação, ou mediação de fato, já que o ser está em relação tão-somente consigo. A dialética do ser e do nada tem como resultado aquilo que Hegel chamará de ser-aí (Dasein): "Para o ser que é mediado, vamos conservar a expressão ser-aí" (HEGEL, 1992, p. 119). O Dasein pode ser tido como o ser-aí, ou como o transitar incessante do ser no nada e do nada no ser, ou seja, o devir tido como resultado é o ser-aí.

A mediação, a relação, é o elemento necessário para o surgimento da realidade, pois não basta a ela só o puro em-si do ser ou do nada. Hegel exemplifica assim tal exigência da relação: tomando a luz e as trevas, vemos que uma não pode subsistir sem a outra, pois é inconcebível que na pura luz, sem qualquer sombra, algo possa ser visto, da mesma forma que na pura treva nada veríamos, para algo ser visto se precisa de luz e treva. Qualquer um tomado somente em si mesmo representa nada mais que o vazio, assim como são ser e nada.

Transitar é a mesma coisa que devir; só que naqueles dois momentos, desde os quais se efetua o trânsito mútuo, são representados mais como repousando um fora do outro, e o transitar se representa como efetuando-se entre eles. Agora, onde e como se quer que se fale do ser ou do nada, tem que estar presente este terceiro; pois aqueles não subsistem por si, senão que existem somente no devir, neste terceiro. (HEGEL, 1992, p. 121)

Como já fora mencionado, Hegel, ao falar do ser e do nada, que estão um fora do outro, está se referindo à teoria de Parmênides, na qual se está no repouso entre um e outro, ou seja, algo é ou não é. O devir se caracteriza em Hegel como o constante transitar entre um e outro, sendo o transitar aquilo que ele tem como um "terceiro", cuja ação gera a identidade do ser e do nada, que "caem" um no outro incessantemente, se mantendo, assim, uma unidade que mantém a diferença entre ser e nada.

nada, e nenhuma coisa é mais clara que sua diferença absoluta, e nenhuma parece mais fácil de declarar. Porém, é igualmente fácil convencer-se de que isto é impossível e que tal diferença é inexpressável. Os que querem obstinar-se na diferença entre o ser e o nada podem ser convidados a declarar em que consiste. Se o ser e o nada tivessem alguma determinação, por cujo meio se diferenciariam, então, como se recordou, seriam um determinado ser e um determinado nada, não o puro ser e o puro nada tal como são, todavia, aqui. Sua diferença, portanto, é completamente vazia e cada um dos dois é da mesma maneira o indeterminado; a diferença, portanto, não subsiste neles mesmos, senão só em um terceiro, no entender." (HEGEL, 1992, p. 119) 
Em suas notas a esse momento da Lógica, Hegel irá criticar a posição de filósofos - como os eleatas e Espinosa (Cf. HEGEL, 1992, p. 109-110) - que conceberam o ser-substância de maneira que desse não se pode sair o negativo ou o finito, se apresenta também a crítica à posição de Jacob Boehme, que defende que não se pode passar do ser puro ao mundo, ao concreto, ao determinado, negando assim a síntese, pois ele não vê como aquilo que é em si inerte, o ser puro, possa oscilar e ganhar movimento por si mesmo para se desdobrar no mundo, no diverso (Cf. HEGEL, 1992, p. 121-134). Hegel mostra que tal posição (a de Parmênides e Espinosa) e tal crítica (Jacob), em se tratando de sua Lógica, não têm sentido, pois não se trata de um indeterminado que seja anterior ao determinado, ou de um universal que seja anterior ao particular, como se do simples nada algo viesse a existir ou ser, já que assim realmente se necessitaria de uma relação extrínseca (como na filosofia de Espinosa). Hegel pondera que em sua Lógica há uma relação intrínseca em seu começo. A máxima que o devir está em tudo não permite que se pergunte onde está e qual é o fundamento originário do mundo. Como Hegel, em sua dialética, imprime uma circularidade no todo da realidade não cabe perguntar com que começa o mundo, pois assim se pressuporia uma causa originária, o que não é o caso.

Isso porque há uma imediatidade no ser e no nada ${ }^{6}$, uma falta ou vacuidade, motivo pelo qual transitam um para o outro, ou seja, um cai no outro de forma imediata, pois não possui sentido algum na unilateralidade, sendo somente na transição ou passagem. ${ }^{7}$ Para fundamentar tal coisa, Hegel afirma ser a não consideração desse caráter intrínseco à realidade, que é a dialética do ser e do nada como começo, uma verdadeira contradição performativa. Para Hegel, isso é uma verdadeira violação do princípio de não-contradição(!):

\footnotetext{
${ }^{6}$ Ainda sobre a relação ser e nada: "Pode, todavia, observar-se, acerca da determinação constituída pelo transitar do ser e do nada um no outro, que este transitar tem que entender-se igualmente sem outra determinação reflexiva ulterior. É imediata e inteiramente abstrata, a causa da abstração dos momentos que, todavia, transitam, vale dizer, porque nestes momentos não se encontra, todavia, posta no ser, pese que na realidade o ser é essencialmente o nada e vice-versa. Não há que conceder, portanto, que se apliquem aqui mediações ulteriormente determinadas e que o ser e o nada se tomem em alguma relação particular. Aquele transitar não é, todavia, nenhuma relação. Não se pode admitir portanto que se diga: o nada é o fundamento do ser, ou bem, o ser é o fundamento do nada, o nada é causa do ser, etc., ou bem, que se possa transitar no nada só com a condição de que algo exista, ou inversamente transitar ao ser só com a condição [da existência] do não-ser." (HEGEL, 1992, p. 133)

${ }^{7}$ Como afirma Hegel: "Na pura reflexão do começo, tal como se a efetua nesta lógica com o ser enquanto tal, o trânsito está, todavia, oculto. Dado que o ser está posto só como imediato, o nada irrompe nele só de modo imediato. [...] neste [ser-aí] está posto o que contém e engendra a contradição, entre aquelas abstrações e, portanto, seu transitar." (HEGEL, 1992, p. 128)
} 
Em qualquer expressão ou rodeio do entendimento que se introduza: quando se resiste contra a unidade do ser e do nada e apela ao que se apresenta, de maneira imediata, não encontrará, precisamente nesta experiência, nada mais que o ser-aí, o ser com um limite, ou uma negação, isto é, aquela unidade que recusa. ${ }^{8}$ (HEGEL, 1992, p. 131)

Quanto ao nada Hegel salienta que ele não tem essência por si mesmo, pois, para Hegel, "o nada é apenas a ausência do ser, e assim as trevas são apenas a ausência da luz" (HEGEL, 1992, p. 132). Note-se que da mesma forma é o ser puro. No exemplo dado, o olho só vê o que está entre a treva e luz, pois algo para ser visto deve estar nessa relação de luz e sombra. Mostra-se assim a necessária relação de algo negativo com o positivo posto, tendo por modelo a relação ser-nada. Mas, salienta que, ao se passar para as coisas determinadas (frio-calor; luz-treva; etc.), não se trata mais de um nada em geral, mas daquilo que Hegel chama negações determinadas.

O princípio dialético aparece como algo inegável ao se contemplar o mundo, a assertiva de que é só pela relação, pelo trabalho do negativo, onde ser e nada estão em tudo, que algo vem a ser e se mantém, pode ser tida como uma "verdade filosófica", se nos é permitido dizer isso, por isso Hegel critica veementemente aos que vêm nisso "algo trivial" e sem importância, ou seja, aqueles que tendem a manter separados o sujeito e o objeto, pensando unilateralmente.

Ambos ser e nada são para Hegel, enquanto momentos em si, meras abstrações, e através de sua dialética não se põe nenhuma existência ainda. Por isso Hegel rechaça a ideia do nada como começo:

Nada pode ter um começo, tanto se existe como se não existe; pois se existe
não inicia primeiramente; porém, se não existe, tampouco inicia. - Se o
mundo ou algo qualquer tivesse que haver começado, teria então que haver
iniciado no nada, porém no nada não há um começo - ou melhor, o nada não
é um começo -; pois o começo inclui em si um ser, porém o nada não inclui
nenhum ser. O nada é apenas o nada. Em um fundamento, em uma causa, etc.
(se se determina assim o nada) se encontra contida uma afirmação, um ser. -
Pelo mesmo motivo não pode sequer cessar de existir algo. Pois então

8 Tal afirmação gera certa surpresa aos críticos do sistema hegeliano que não consideram racional sua lógica dialética justamente por contradizer, segundo tais críticos, o citado princípio, e os surpreenderá mais ainda a enfática colocação de Nöel (1933, p. 15): "Em seu sentido, o método hegeliano é evidentemente uma aplicação contínua do princípio de contradição." 
deveria o ser conter o nada, porém o ser é apenas ser, e não o contrário de si mesmo. (HEGEL, 1992, p. 134)

A crítica hegeliana recai sobre todos aqueles que não concebem a relação dialética na qual não há separação entre ser e nada, ser e nada são inseparáveis. Hegel salienta que por mais que se tente separá-los sempre se explicita mais a dialética dessa relação: "a representação deixa valer um começar e um cessar de existir como determinações igualmente verdadeiras, e, com isto, já admite de fato a inseparabilidade do ser e do nada", pois, "não se dá absolutamente nada que não seja una situação intermediária entre o ser e o nada" (HEGEL, 1992, p. 134).

\section{Bibliografia}

HEGEL, G. W. F., Ciencia de la Logica, 2 vol. $6^{\mathrm{a}}$ ed., Tradução de Augusta e Rodolfo Modolfo, Buenos Aires: Librarie Hachette, 1992.

KIERKEGAARD, S. A., Abschliessend unwissenschaftliche nachschrift zu den philosophischen Brocken. In: Gesammelte Werke, 2aed., Gütersloh: Ed. E, Hirsch / H. Gerdes, 1991, vol. 13, p. 106. apud. LUFT, E., As sementes da dúvida: Investigação crítica dos fundamentos da filosofia hegeliana, São Paulo: Editora Mandarin, 2001.

GADAMER, H.-G., La dialéctica Hegel - Cinco ensayos hermenéuticos, 5a ed., Tradução de Manuel Garrido, Madrid: Ediciones Cátedra, 2000.

HYPPOLITE, J., Logique et existence - Essai sur la logique de Hegel, $3^{\mathrm{a}}$ ed., Paris: Presses Universitaires de France, 1991.

NOËL, G., La Logique de Hegel, Paris: Librairie Philosophique J. Vrin, 1933.

WAHL, J., Commentaires de la Logique de Hegel, Paris: Centre de Documentation Universitaire, 1959. 